\title{
Condiciones para el Cultivo de la Vid en Época Romana a través de Columela y los SIG
}

\author{
Conditions for Vine Cultivation in Roman Times through \\ the Columella and GIS \\ Pedro Trapero-Fernández \\ pedro.trapero@uca.es 10000-0001-5808-054X \\ Área de Historia Antigua, Departamento de Historia, Geografía y Filosofía. \\ Facultad de Filosofía y Letras. Universidad de Cádiz. Av. Dr. Gómez Ulla, 1. 11003 Cádiz.
}

\section{INFO ARTÍCULO}

Recibido: 07-07-2020

Revisado: 22-11-2020

Aceptado: 05-12-2020

\section{PALABRAS CLAVE}

Viticultura romana

Columela

SIG

Agronomía antigua

Hasta Regia

\section{KEYWORDS}

Roman viticulture

Columella

GIS

Ancient agronomists

Hasta Regia

\begin{abstract}
RESUMEN
El viñedo requiere de unas características edafológicas y de localización para su cultivo, cosa que, en época Antigua, conocemos gracias a los agrónomos latinos como Lucio Junio Moderato Columela. En estas obras encontramos referencias a las diversas tipologías de suelos, pendiente y orientación, así como los criterios preferentes para la elección del lugar de cultivo. En este artículo se compara el conocimiento antiguo con las Ciencias de la Tierra actuales, utilizando como puente de unión los Sistemas de Información Geográfica. Además, expresamos un caso de estudio con una lectura precisa de las fuentes clásicas, especialmente Columela y su interrelación, con el objeto de poder modelar un territorio, la colonia de Hasta Regia (Provincia Ulterior Baetica) y las condiciones de esta producción agrícola. Este artículo propone un modelo SIG sobre la viticultura antigua y una correlación entre fuentes escritas y condicionantes geográficos actuales, parámetros necesarios para este modelo y futuros estudios.
\end{abstract}

\begin{abstract}
For crop vineyards it is requires an edaphological and location characteristics. In Ancient Times we knew their through the latin agronomists like Lucio Junio Moderato Columela. In these books, we found references about the soil, slope and orientation classification typologies as main conditions for choose the cultivation place. We compare the ancient knowledge with actual soil sciences, using for integrate them the Geographical Information Systems. In this paper, we propose a careful reading of ancient sources, especially Columella, applied in a study case the Hasta Regia colony (Baetic province) for modelling the territory and agricultural production conditions. The article seek to propose a GIS model about ancient viticulture with the correlation between written sources and actual geographical conditions, both needed parameter for the model and future studies.
\end{abstract}




\section{INTRODUCCIÓN}

A la hora de elegir un espacio para un nuevo cultivo, el agricultor selecciona, entre los distintos tipos que tiene, las tierras más viables. Actualmente, esto se puede realizar con gran precisión gracias a los estudios de Ciencias de la Tierra como la edafología. En el mundo antiguo no se tenía un conocimiento tan avanzado respecto a las necesidades de las plantas y las propiedades físico-químicas del suelo; pese a ello, los agrónomos romanos nos han legado un importante número de referencias relativas a la elección del tipo de suelo para cada cultivo. Dentro de ellos, destaca la vid como uno de los cultivos más complejos, al necesitar más inversión y, a su vez, por el mayor rendimiento económico que puede reportar. En este artículo, se desarrollan cuáles serían los condicionantes básicos necesarios para establecer un viñedo en época romana, teniendo como referencia el análisis de las fuentes agronómicas, especialmente Lucio Junio Moderato Columela. Junto con este análisis, se plantea la extrapolación de estos requisitos a sus paralelos actuales, reconociendo estas tipologías con las contemporáneas, mediante el uso de los SIG.

Se parte de la consideración que la vid puede ser cultivada en multitud de espacios, aunque la agronomía romana refiere factores físicos como el suelo, orientación, pendientes u otras características que pueden favorecer este cultivo. Sabemos que las villae romanas tendrían una producción mixta de diversos recursos para garantizar su propia subsistencia, aunque sí puede existir cierta especialización de un cultivo, como es el viñedo, dado su mayor rendimiento económico (el Bouzidi, 2003). La vid, como planta, es una de las más caras en su cultivo y de las que mayor cuidado requiere (Sáez, 1988; Goodchild, 2007). La primera cuestión importante a este respecto, más allá de escoger un buen personal para cuidar de la viña (Columella, Rust. 1.9.6.) ${ }^{1}$, es la elección del suelo de cultivo, la altura y pendiente del mismo, así como la orientación respecto a los vientos y la insolación potencial.

En este artículo se analiza, como caso de estudio, el ámbito de la colonia romana Hasta Regia, en el suroeste de la Península Ibérica. Se trata de un espacio con una posible especialización en el cultivo del viñedo (Trapero, 2020) y cuyo territorio ha sido ampliamente estudiado por el laboratorio de Historia del IVAGRO (Ruiz et al., 2019). Es un lugar de estudio idóneo para poner en relación los criterios antiguos con factores actuales, especialmente porque actualmente la zona es una importante productora de vinos a nivel internacional como es el Marco de Jerez (Figura 1).

Además, se trata de una colonia vecina a Gades, de donde era originario Columela. Este autor agronómico será, por tanto, el principal referente para este estudio, no sólo por las posibles referencias indirectas a su territorio de origen, sino por ser el agrónomo más completo en temas de viticultura y, especialmente, por las referencias a su tío Marco Columela, agricultor Bético, tratándose, de este modo, de información de primera mano para conocer la viticultura en la zona de estudio. Nuestro principal objetivo, por tanto, es el análisis de la correlación entre estas características descritas en las fuentes antiguas con las actuales, mediante una lectura atenta de los agrónomos latinos y su relación mediante los Sistemas de Información Geográfica con los condicionantes actuales.

La investigación aporta un modelo de análisis territorial con SIG mediante el cual poder estimar los lugares óptimos para la viticultura antigua cuya base ya fue publicado previamente (Trapero, 2016a y 2016b). En ellos se esbozó el método partiendo de datos de hace más de cuarenta años (Sáez, 1988), que aquí se analizan de manera pormenorizada, viendo los aspectos a considerar para fusionar fuentes escritas y condicionantes físicos actuales. 


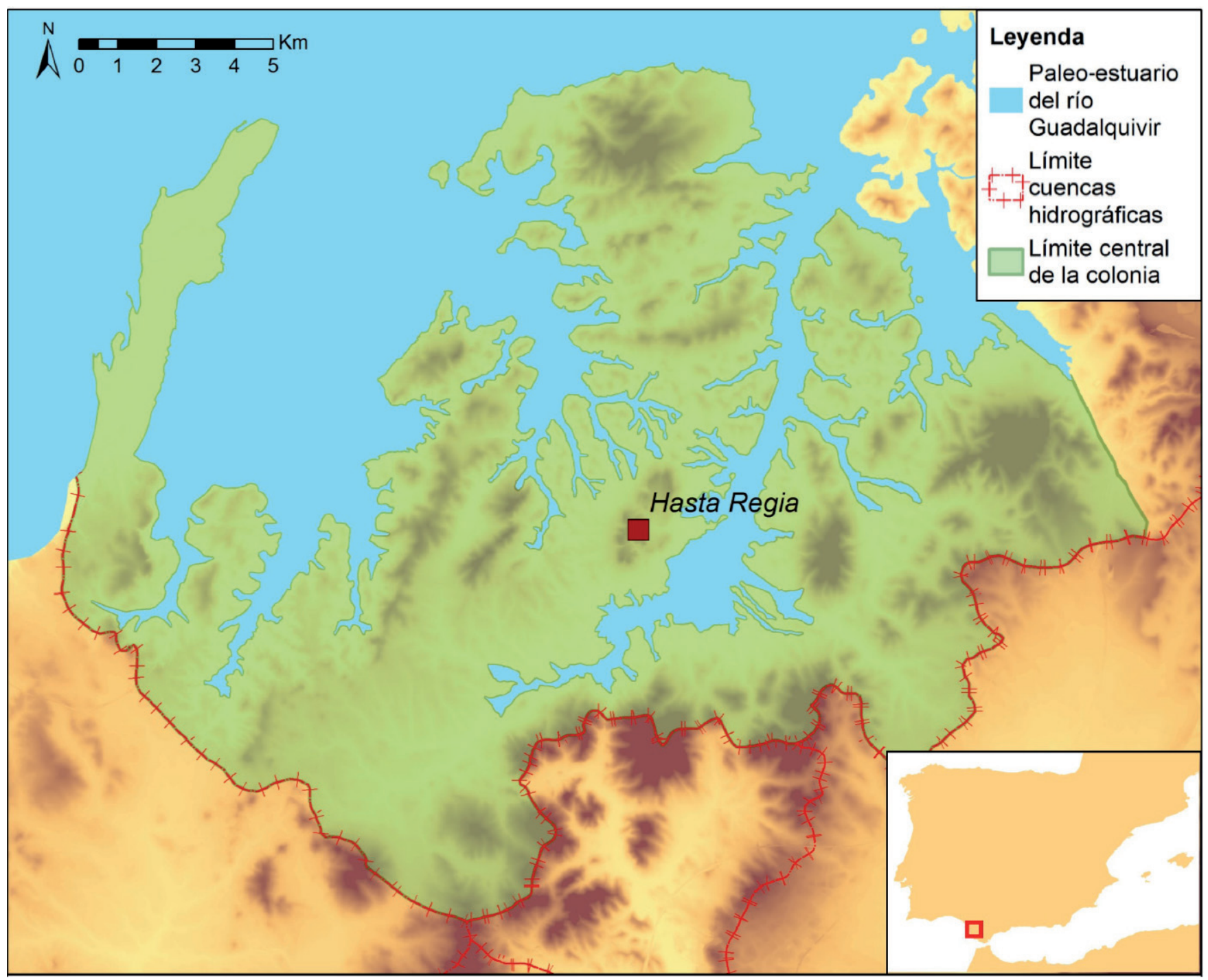

Figura 1. Territorio de estudio en torno a Hasta Regia. Fuente: Elaboración propia.

\section{TEORÍA}

Tenemos que partir, por tanto, del conocimiento que tendrían los romanos de las condiciones del suelo y hasta qué punto serían capaces de describirnos características, que nos sirvan en la actualidad para relacionarlas con elementos naturales. En general, estas ideas básicas ya están expresadas al menos desde Teofrasto (Historia Plantarum, 1.8.1.), por lo que gran parte de este saber natural debe beber de la literatura griega. Las condiciones principales que se tratan son, en esencia, cuatro: la tipología de suelo, los vientos que azotan, la pendiente del terreno y la insolación potencial. De entre los distintos autores, Columela es el principal para esta investigación, por sus referencias directas al área de estudio y su profundo conocimiento agronómico, especialmente para el cultivo de la vid (García, 1995).

Parece que estos son los criterios básicos para el establecimiento de un nuevo viñedo, pero también son los que se utilizan para otro tipo de cultivos. Estas cuestiones son relevantes en contextos de implantaciones nuevas, como pudo ser el caso de la deductio colonial de Hasta Regia (Martín-Arroyo, 2018). El entorno de esta colonia se ha venido identificando como una importante zona productora de vinos desde hace ya muchos años (Tovar, 1975; Larrea, 1975), hecho que queda confirmado a través de la cultura material (Carreras, 2001). El área de estudio ha tenido varios trabajos que engloban perspectivas, pasando del análisis de la agricultura previa a la romana (Carretero, 2007), hasta la propia ordenación territorial de esta ciudad y las colindantes (García et al., 2008; Lagóstena 2014). 
Todas estas cuestiones ya han sido analizadas por P. Sáez Fernández, en su libro sobre la Agricultura romana de la Bética (1987). Partimos de esta investigación que analiza los condicionantes para la agricultura en general y el viñedo y olivar en particular. A este amplio análisis añadimos parte de la bibliografía que complementa y desarrolla gran parte de estas cuestiones (White, 1975; Sirago, 1975; Rees, 1979; Kolendo, 1980; Marcone, 1997; Bowman \& Wilson, 2013). Existen otros trabajos de relevancia en este período que complementan esta información, pero en otras zonas de estudio (Tchernia, 1986; Revilla, 1995; Brun, 2003).

El objetivo ha sido conseguir una mejor lectura de las referencias de los agrónomos latinos en especial, aunque también de otros autores que realizan obras de carácter agronómico, como Virgilio o Plinio el Viejo, para poder relacionar dichas referencias a los suelos actuales y sus características edafológicas (Porta et al. 2003). La interrelación entre estos condicionantes y sus paralelos actuales han sido analizadas en trabajos recientes gracias a los Sistemas de Información Geográfica (Goodchild, 2007; Trapero, 2016a; Martín et al., 2017; Martín-Arroyo \& Remesal, 2018). Partimos de este enfoque, con el objeto de analizar una información que lleva varias décadas sin actualizarse (Sáez 1983, 1987, 1988, 1995).

\section{METODOLOGÍA}

El método empleado parte de la lectura atenta de las fuentes clásicas, especialmente los agrónomos tanto latinos como posteriores. Se añadirán los fragmentos que sean relevantes junto a su traducción al casteIlano (de Herrera, 1818; Días-Regañon, 1988; Holgado, 1988; Moure, 1990; Vidal, 1990; AA.V., 1998; Cuber, 2003, 2010; Marzanero et al. 2010). Se han analizado aquellos condicionantes en esta literatura que tengan relación directa con la viticultura y cuyos parámetros pueda haber sino inalterables con el paso del tiempo (André, 1981; Arias, 1987). En este sentido, Columela ha sido el autor clave, por ser el más completo referente de esta literatura romana, pero también por sus amplias referencias sobre la viticultura y el territorio a estudiar. El resto de autores agronómicos se han utilizado esencialmente para calibrar las diversas referencias e interpretaciones.

Desde el punto de vista historiográfico, Sáez (1987) ya trató todas estas cuestiones. Por tanto, partiendo de estas hipótesis de correlación, por ejemplo, entre tipos de suelos citados en las fuentes y los actuales, buscamos argumentos que defiendan o desestimen dicha relación. Por ello se han analizado las diferentes palabras clave de esta literatura, comparándola con otros autores antiguos para definir con claridad la acepción y posible asociación entre las palabras. Estas cuestiones estarán expresadas en tablas en los diversos apartados de este artículo.

Con estos datos, pasamos a analizar el reflejo actual que pueda tener en el territorio a través de los Sistemas de Información Geográfica. Esta investigación complementa y amplía la metodología expuesta en un artículo previo (Trapero, 2016a, 2016b). El método consiste en combinar los diversos condicionantes, en este caso tipologías de suelo, pendientes y orientación, para crear un modelo de zonas potenciales, que nos permita poder responder a diversas preguntas. En primer lugar, saber los lugares óptimos para la viticultura romana, que probablemente se implantaría con deductio colonial de Hasta Regia. En segundo lugar, permitiría visualizar y analizar los resultados relacionando si la viticultura actual está en consonancia con la antigua. Esto también puede servir como un instrumento de control y autocrítica, pues permite revisar los resultados para establecer una visión más objetiva de la correlación de tipologías antiguas y actuales, pero también del método a emplear.

Expondremos subapartados para el método de análisis concreto por cada condicionante. Estos han sido elegidos a través de la lectura crítica de las fuentes antiguas, por lo que podemos ver que el tipo de suelo, orientación y pendiente son los principales. Un segundo criterio es su capacidad de representación actual a través de los SIG, siendo parámetros que no han sido alterados en el tiempo y pueden calcularse en un modelo con precisión. Pudieran existir una serie de condicionantes humanos, que ya han sido considerados previamente (Trapero, 2016a), pero que no requieren de una interpretación ni lectura especial, como vamos a hacer ahora. 


\subsection{Tipología de suelos}

El primer condicionante, y el más importante, es la tipología de suelos. La descripción de estos por parte de los agrónomos es poco detallada. No existe un estudio edafológico como tal y, por tanto, las asimilaciones entre los distintos tipos de suelos mencionados por los agrónomos latinos con los actuales son difíciles de precisar (Olson, 1943). Solamente en Columela vemos una preocupación real por explicar los tipos de suelos, cosa que para autores como Catón (Agr. 1.2-3.)² o Varrón (R.R. 1.9.) es de menor importancia, pues sus referencias son más laxas. En general, se suelen clasificar las tierras a partir de tres características: pingüe frente a magro, suelto frente a compacto y húmedo frente a seco (Teofrasto Causis Plantarum 2.5.9).

Columela (Rust. 2.2.1-21) y Plinio (HN Hist. 17.3-4) describen mejor las características del suelo, Virgilio también le da importancia, aunque su referencia es más breve (Virgil, Geor. 2.230-260). En sus obras se tiene en consideración cuestiones más fundamentales, como el granulado de la tierra, la compactación, o la capacidad de retención de agua. Encontramos en Paladio (1.5.) unas descripciones similares, aunque menos desarrolladas, que probablemente estén basadas en las de Columela y Plinio. En las Geopónicas (2.9-13) se destinan tres apartados a describir esta realidad de manera exhaustiva, pero con la misma percepción. En la agrimensura medieval, encontramos en el capítulo primero de Ibn al Awam (2003) la más desarrollada descripción de estas características, basada en Columela y autores árabes, pero teniendo el mismo concepto de fondo. Finalmente, en Alonso de Herrera (1.2.13 y 1.24-4) es donde, por primera vez, encontramos un proceso que busca analizar la naturaleza del suelo mediante la decantación y separación de los diversos componentes del mismo. Podemos ver diferencias en la composición del suelo según esté formado por greda, arena, arcillas, etc. Sobre todas estas cuestiones existe la propuesta de Sáez (1987), en la que se asocian las tres mejores tierras del marco del Jerez, albariza, barros y arenas, con las tierras en las que tenía viñas Marco Columela (Tabla 1).

Queremos aquí, partiendo de esta hipótesis, desarrollar y precisar mejor algunas claves para el reconocimiento de este tipo de suelos con los actuales. Concretamente, en la zona de estudio nos encontramos con unas tipologías edafológicas, que están reguladas según las normativas europeas (FAO, 2019). Para el territorio de la zona comprendida por Hasta Regia, tenemos los siguientes grupos de suelos generales y sus correspondientes superficies (Tabla 2):

La mayor parte de los suelos de la zona de estudio (Figura 2) están compuestos por vertisoles; seguidos de regosoles; sobre todo los calcáreos; cambisoles y, en menor medida, solanchaks. Exponemos a continuación una breve descripción de estos tipos generales de suelos, partiendo de datos básicos para su comprensión y organizándolos de mayor a menor idoneidad de las diversas tipologías para viticultura (García, 1988):

- Regosoles: tierras erosionadas pero consolidadas, cuyo uso en muchos lugares es pobre, generalmente reservado para pastos. Para el bajo Guadalquivir se trata del antiguo lecho marino de composición calcárea. Estos suelos son denominados, en la región de Jerez, albarizas y son los suelos preferidos para la producción vitivinícola.

- Vertisoles: tierras negras con una alta composición arcillosa situadas en áreas llanas o suavemente onduladas. Son suelos duros y que se agrietan en verano, mientras que se vuelven plásticos e inundables en invierno. En la zona se les llama "bujeo" y son buenos para el cultivo del grano.

- Luvisoles: tierras de lavado de arcillas, asociadas normalmente con depósitos aluviales, fértiles por la combinación de ambas.

2. Repárese en cómo es de próspera la situación de los vecinos: una región que sea buena, debe ser muy rica; que sea de fácil acceso y su recorrido y salida posibles; goce de buen clima, no esté expuesto a la helada, y tenga valor por la buena calidad de su suelo, por su fertilidad. Sí es posible, que esté situado al pie de un monte, orientado al sur, en lugar sano; Haya abundancia de trabajadores, y que tenga fuentes de aguas, y una ciudad importante se encuentren cerca, o el mar, o un río navegable o una vía bien construida y transitada. Vicini quo pacto niteant, id animum advertito: in bona regione bene nitere oportebit. Et uti eo introeas et circumspicias, uti inde exire possis. Uti bonum caelum habeat; ne calamitosum siet; solo bono, sua virtute valeat. Si poteris, sub radice montis siet, in meridiem spectet, loco salubri; operariorum copia siet, bonumque aquarium, oppidum validum prope siet; aut mare aut amnis, qua naves ambulant, aut via bona celerisque. 
- Arenosoles: este tipo de suelo aparece sobre dunas recientes, lomas de playas o llanuras arenosas con una vegetación herbácea pequeña. Su mayor limitación para la agricultura es su asociación con el agua salada. En la zona de estudio, su uso agrícola es tradicional, mediante la técnica de navazos o aportes de tierras (López y Ruiz, 2007).

- Cambisoles: depósitos aluviales o eólicos que configuran la mayor parte de las llanuras. Son tierras en general buenas para cualquier uso agrícola.

- Fluvisoles: tierra de depósitos aluviales fértiles pertenecientes a las terrazas más próximas a ríos o lagos. Generalmente no son muy óptimas para la agricultura por ser zonas inundables, a menos que se contengan las crecidas.

- Rendzina: suelo rico con alto contenido en piedra caliza, poco abundante en la zona, aunque sí lo es en la sierra de Cádiz.

- Planosoles: regiones estacionalmente inundadas, con o sin alto contenido salino y pobres para la agricultura.

- Gleysoles: tierra constantemente cubierta por agua, fondos de lagos y ríos.

- Solanchaks: suelos de marisma con alta concentración de salinidad. Son los suelos de marisma actual o antigua marisma, que en nuestros días tienen un uso agrícola pobre, dedicándolos principalmente a la ganadería.

- Litosoles: afloramientos de rocas en superficie, tipo de suelo de sierra, con una potencia muy débil que solo soporta pequeña vegetación herbácea. Zonas que se dejan baldías o se reservan a la ganadería, como la caprina.

Relacionar estas tipologías de suelos con las descripciones que nos dan los agrónomos latinos resulta en principio difícil por no disponer de todos los datos, ya que las fuentes no nos hablan de características físico-químicas de los suelos.

\subsection{Pendiente del terreno}

Respecto a la pendiente, ya hemos visto en parte de los textos anteriores referencias a la distinta morfología del terreno. Estas características son comunes a todos los agrónomos y se resumen perfectamente por Varrón, (R.R. 3.18.2), donde los granos se situarían en la llanura, las viñas en colina y los bosques en montañas.

Columela recomienda algo similar específicamente para las viñas (Rust. 3.1.8.) ${ }^{3}$, por lo que pudiera ser una máxima que los agrónomos romanos respetarían. Es algo lógico destinar los tipos de suelos dependiendo de su calidad y, en este caso, la calidad depende de la elevación y pendiente de los mismos. Sin duda, un suelo de montaña no es óptimo para la agricultura, y sus aprovechamientos se orientarían más hacia actividades cinegéticas, forestales o, directamente, ganaderas (Kolendo, 1980, p. 185).

A su vez, las colinas suelen ser los lugares reservados para el cultivo de la vid y el olivo. Sin embargo, ya hemos comentado que Marco tendría viñas tanto en colina, como en llano palustre. Esta dicotomía expresa la adaptación que hace el agricultor de las viñas, fruto de su enorme conocimiento agronómico, para poder conseguir determinadas variedades de vino. Sin embargo, a grandes rasgos, podemos deducir que los llanos estarían principalmente reservados para el cultivo de cereales, como base de la alimentación. Para el caso concreto de estudio, las lomas no son muy pendientes y es por ello que en la actualidad no existe realmente una diferenciación importante entre cultivar una suave colina de cereal o de viña, más allá de la tipología edafológica del suelo. Partiendo de una capacidad de intervención y productividad más bajas que

3. Si se puede elegir el lugar y el clima para las viñas según el propio deseo, el suelo mejor es, como piensa muy acertadamente Celso, el que no es ni demasiado compacto ni suelto, si bien más cercano al suelto; ni pobre ni muy rico, sino próximo al rico; ni llano ni en pendiente, más bien parecido a una llanura en declive At si voto est eligendus vineis locus et status caeli, sicut censet verissime Celsus, optimum est solum nec densum nimis nec resolutum, soluto tamen propius; nec exile nec laetissimum, proximum tamen uberi; nec campestre nec praeceps, simile tamen edito campo. 
las actuales mecanizadas, sí pudiera existir una diferenciación en la dificultad entre roturar zonas llanas o en colina. Hay que recordar en relación con este aspecto, que gran parte de estas zonas durante la conquista cristiana ya estaban cultivadas de olivos o viñas, por lo que es una práctica que viene desde antiguo para el lugar de estudio (Martín, 1999).

Tabla 1. Distinta percepción de los tipos de suelos en autores agronómicos y la correlación hecha por Sáez 1987.

\begin{tabular}{|c|c|c|}
\hline Autor & Referencia & Información sobre suelos \\
\hline Teofrasto & Historia Plantarum, 1.8.1. & $\begin{array}{l}\text { Primera referencia completa conocida sobre los tipos de suelo. } \\
\text { En su descripción sobre las plantas habla de las propiedades } \\
\text { del suelo, aunque no desde parámetros agronómicos }\end{array}$ \\
\hline Catón & Agr. 1.2-3. & $\begin{array}{l}\text { No especifica más que se tiene que buscar un buen tipo de } \\
\text { suelo }\end{array}$ \\
\hline Varrón & R.R. 1.9. & $\begin{array}{l}\text { Diferencia tres tipos con sus contrapuestos: Pedregosa/Arcillo- } \\
\text { sa, Húmeda/Seca y Pingüe/Magra (este último hace referencia } \\
\text { a la calidad de la tierra si es pobre o rica) }\end{array}$ \\
\hline Virgilio & Geor. 2.230-260 & $\begin{array}{l}\text { Descripción breve pero enfocada en la práctica para el agricul- } \\
\text { tor }\end{array}$ \\
\hline Columela & Rust. 2.2.1-21 & $\begin{array}{l}\text { Descripción más completa con crítica de las fuentes anteriores } \\
\text { y experimentación personal. Se puede observar que sigue la } \\
\text { misma clasificación que Varrón, ya que solamente pueden clasi- } \\
\text { ficar la tierra por sus cualidades físicas }\end{array}$ \\
\hline Plinio el Viejo & HN Hist. 17.3-4 & $\begin{array}{l}\text { Basado en Columela, añadiendo algunas referencias que com- } \\
\text { plementan los casos de estudio }\end{array}$ \\
\hline Paladio & 1.5 & Descripción breve basada en la literatura anterior \\
\hline Geopónicas & $2.9-13$ & Descripción desarrollada basada en literatura anterior \\
\hline Ibn al Awam & 1 & $\begin{array}{l}\text { Descripción desarrollada basada en Columela y otros autores } \\
\text { árabes, pero sin mejor conocimiento de los tipos de suelo, aun- } \\
\text { que si amplia los tipos de suelos }\end{array}$ \\
\hline Alonso de Herrera & 1.2 .13 y $1.24-4$ & $\begin{array}{l}\text { Desarrollo de los tipos de suelo conociendo sus características } \\
\text { físicas y químicas. Tenemos ya un estudio edafológico }\end{array}$ \\
\hline Interpretación actual & (Sáez 1987) & $\begin{array}{l}\text { Se asocian los tipos de tierra, especialmente descritos por Colu- } \\
\text { mela en base a sus características físicas con los tipos de suelos } \\
\text { más usados para la viticultura en la región del Marco del Jerez }\end{array}$ \\
\hline
\end{tabular}

Fuente: Elaboración propia.

Sin duda, partiendo de la crítica que hace Columela a las zonas baldías y grandes extensiones de tierra que no se ponen en cultivo, se une a la idea del rendimiento económico que tiene la vid (Witcher, 2006), por lo que podríamos preguntarnos si en un espacio especialmente pródigo para el cultivo de la vid, ésta se situaría ocupando zonas tradicionalmente de cereal. Sin duda, tenemos en Marco Columela el caso más claro de uso del llano, si bien, puede no ser el mejor ejemplo.

Modelar estos espacios es posible utilizando un MDS, Modelo Digital de Superficie que, en nuestro caso se trata de un raster de cinco metros de resolución. Con esta base se pueden aplicar herramientas de SIG como Spatial Analysis/Surface/Slope de Arcgis para calcular las pendientes del terreno (Figura 3). Así es posible la caracterización de estos espacios de llano, colina y montaña en base a conocer la propia pendiente del terreno y los cambios en la misma. Sin duda interesa en este aspecto conocer la altura relativa donde aparecen dichas colinas, pero la cuestión relevante a este asunto es que la colina sería un espacio preferente para el viñedo, ya que puede ser cultivado perfectamente con cierta inclinación, algo que podría dificultar otra serie de cultivos. 
Tabla 2. Tipologías de suelos en el territorio con sus porcentajes.

\begin{tabular}{|c|c|c|c|}
\hline $\mathrm{N}^{\circ}$ & Unidades edáficas & Área ha & $\%$ \\
\hline 1 & Solonchaks takírico y Solonchaks gleicos & $2.633,86$ & 9,535 \\
\hline 2 & $\begin{array}{l}\text { Regosoles Calcáreos y Cambisoles cálcicos con litosoles, Fluviosoles calcá- } \\
\text { reos y Rendsinas }\end{array}$ & $1.725,13$ & 6,245 \\
\hline 3 & Regosoles éutricos, Regosoles dístricos y Aerosoles álbicos & 451.21 & 1,633 \\
\hline 4 & $\begin{array}{l}\text { Vertisoles crómicos y Cambisoles vérticos con Cambisoles cálcicos, Regosoles } \\
\text { calcáreos y Vertisoles pélicos }\end{array}$ & $2.070,66$ & 7,496 \\
\hline 5 & Vertisoles pélicos, Rendsinas y Regosoles calcáreos & $4.738,17$ & 17,152 \\
\hline 6 & Vertisoles pélicos y Vertisoles crómicos & 291,82 & 1,056 \\
\hline 7 & Arenosoles álbicos, Cambisoles húmicos y Gleysoles dístricos & $1.191,80$ & 4,314 \\
\hline 8 & Vertisoles pélicos, Rendsinas y Regosoles calcáreos & 554,70 & 2,008 \\
\hline 9 & Sin dato & 15,10 & 0,045 \\
\hline 10 & Regosoles éutricos, Xerosoles hápilicos y Litosoles & 134,19 & 0,486 \\
\hline 11 & Vertisoles pélicos, Rendsinas y Regosoles calcáreos & 124,90 & 0,452 \\
\hline 12 & $\begin{array}{l}\text { Vertisoles crómicos y Cambisoles vérticos con Cambisoles cálcicos, Regosoles } \\
\text { calcáreos y Vertisoles pélicos }\end{array}$ & $1.922,39$ & 6,959 \\
\hline 13 & Vertisoles pélicos, Rendsinas y Regosoles calcáreos & $2.247,22$ & 8,135 \\
\hline 14 & $\begin{array}{l}\text { Cambisoles vérticos, Regosoles calcáreos y Vertisoles crómicos con Cambiso- } \\
\text { les cálcicos }\end{array}$ & 78,67 & 0,285 \\
\hline 15 & Vertisoles pélicos y Vertisoles crómicos & 857,27 & 3,103 \\
\hline 16 & $\begin{array}{l}\text { Cambisoles cálcicos, Luvisoles cálcicos y Luvisoles crómicos con Litosoles y } \\
\text { Fluvisoles calcáreos }\end{array}$ & 411,20 & 1,489 \\
\hline 17 & $\begin{array}{l}\text { Regosoles Calcáreos y Cambisoles cálcicos con litosoles, Fluviosoles calcá- } \\
\text { reos y Rendsinas }\end{array}$ & $2.838,65$ & 10,276 \\
\hline 18 & $\begin{array}{l}\text { Regosoles Calcáreos y Cambisoles cálcicos con litosoles, Fluviosoles calcá- } \\
\text { reos y Rendsinas }\end{array}$ & 280,11 & 1,014 \\
\hline 19 & Vertisoles pélicos, Rendsinas y Regosoles calcáreos & 326,97 & 1,184 \\
\hline 20 & $\begin{array}{l}\text { Vertisoles crómicos y Cambisoles vérticos con Cambisoles cálcicos, Regosoles } \\
\text { calcáreos y Vertisoles pélicos }\end{array}$ & 102,65 & 0,372 \\
\hline 21 & Luvisoles cálcicos, Luvisoles crómicos y Luvisoles gleicos & 258,17 & 0,935 \\
\hline 22 & Vertisoles pélicos y Vertisoles crómicos & 3672,49 & 13,294 \\
\hline 23 & Luvisoles cálcicos, Luvisoles crómicos y Luvisoles gleicos & 10,68 & 0,039 \\
\hline 24 & Luvisoles crómicos Cambisoles cálcicos y Litosoles & 41,03 & 0,149 \\
\hline 25 & $\begin{array}{l}\text { Regosoles Calcáreos y Cambisoles cálcicos con litosoles, Fluviosoles calcá- } \\
\text { reos y Rendsinas }\end{array}$ & 155,94 & 0,565 \\
\hline 26 & $\begin{array}{l}\text { Regosoles Calcáreos y Cambisoles cálcicos con litosoles, Fluviosoles calcá- } \\
\text { reos y Rendsinas }\end{array}$ & 272,83 & 0,988 \\
\hline 27 & Vertisoles pélicos, Rendsinas y Regosoles calcáreos & 216,38 & 0,783 \\
\hline
\end{tabular}

Fuente: Elaboración propia. 


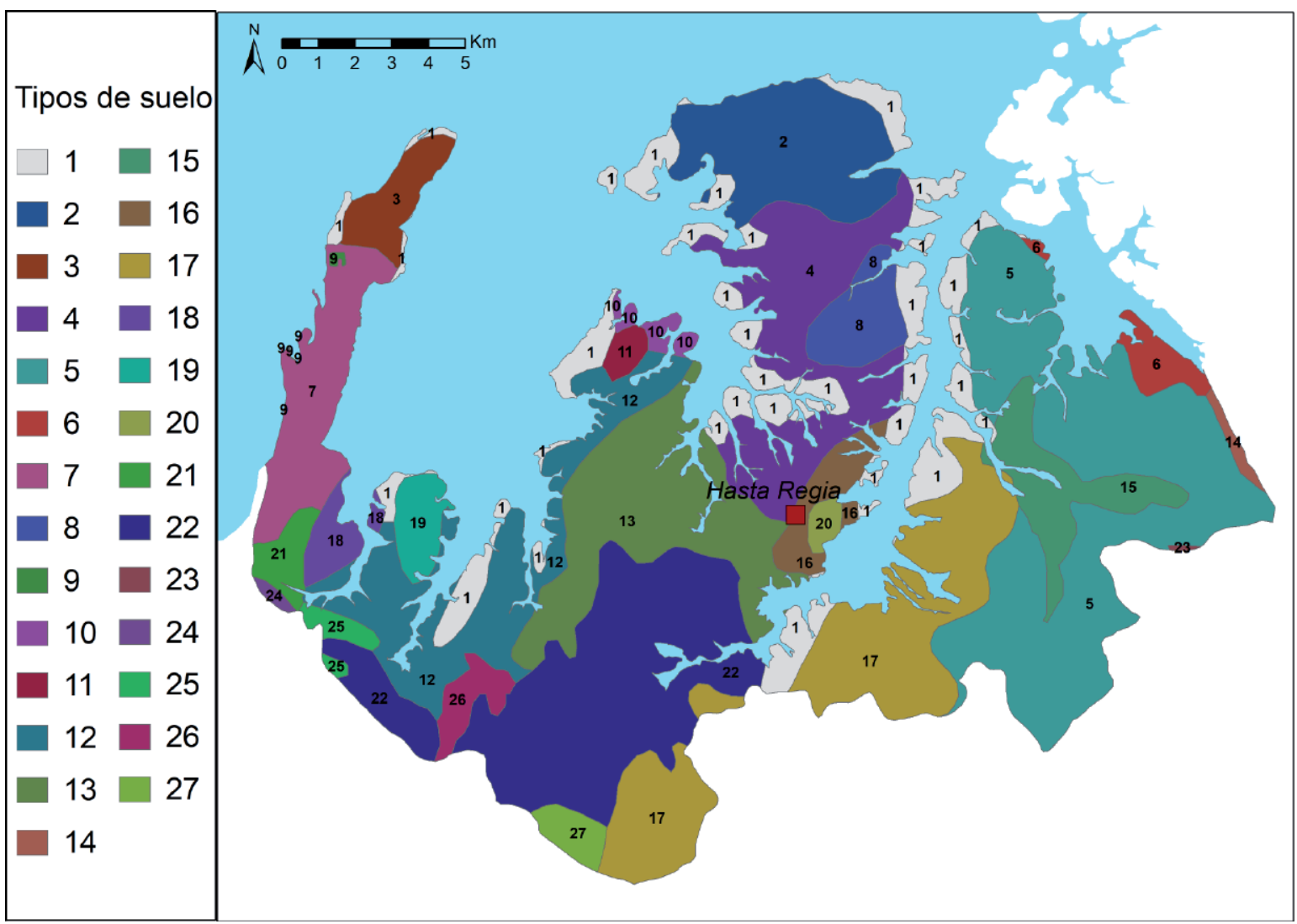

Figura 2. Tipologías de suelos en la zona de estudio. Fuente: Elaboración propia.

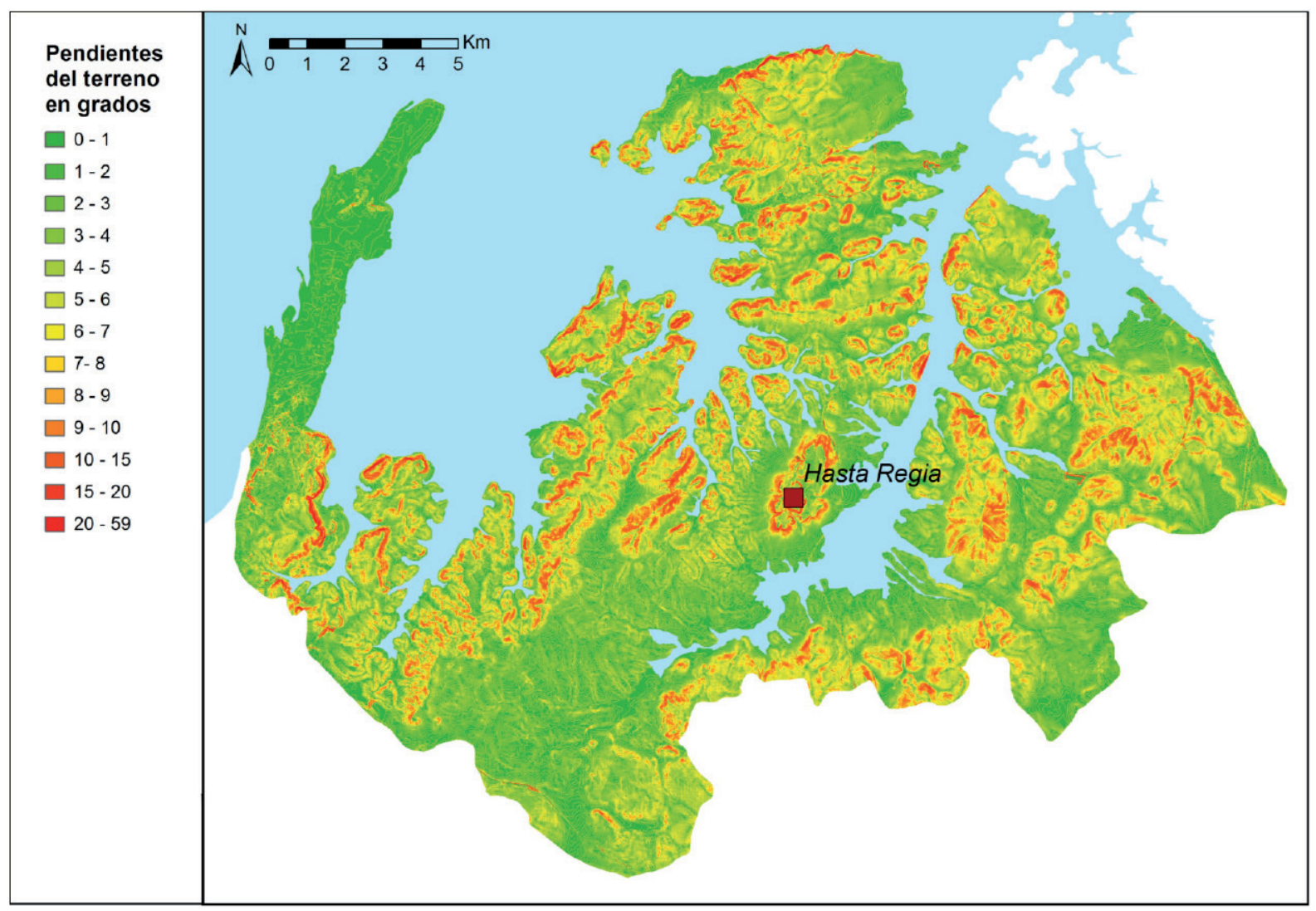

Figura 3. Pendientes del terreno expresadas en grados. Fuente: Elaboración propia. 


\subsection{Orientación del terreno}

Otro de los criterios primordiales que utilizan los agrónomos respecto a las tierras, es la orientación de la misma. En este sentido, hay dos realidades que se contraponen, como veremos a continuación, la orientación del viento y la insolación. Ambos criterios dependen de la posición de la viña respecto a la orografía, especialmente en los casos en los que el viento pueda dañarla, o en lugares donde la insolación potencial no sea importante. Respecto a los vientos (Columella, Rust. 3.12.6.):

Demócrito y Magón ponderan la excelencia del campo orientado al norte, pues piensan que las vides se harán muy productivas con esta orientación, aunque se vean superadas con relación a la buena calidad de su vino. A nosotros nos ha parecido lo mejor aconsejar, como regla general, que en lugares fríos las vides miren al mediodía, y en los tibios, al Levante, siempre y cuando no las maltraten el Austro y el Euro, como sucede en las costas de la Bética. Si las regiones estuvieran castigadas por estos vientos, mejor será orientarlas al Aquilón y al Favonio4.

Esta recomendación de Columela es también una constante en otros agrónomos romanos, al menos Virgilio la usa de manera similar para las viñas (Geor. 2.184-194 y 2.298) ${ }^{5}$, mientras que Catón y Varrón también hacen algunos comentarios generales al respecto (Trapero, 2016b, p. 62).

Parece claro que la mayoría de los vientos predominantes secos suelen ser malos para la agricultura, situación que conocían los agrónomos, especialmente Columela. En general, si se puede elegir el espacio de cultivo para el viñedo, se pondera una orientación hacia el Levante, Sureste, salvando casos concretos como el que menciona para la Bética, donde calcula mejor dicha orientación hacia el Norte u Oeste. Esto pudiera resultar algo extraño, pero corresponde con una realidad climática muy típica de la costa de Cádiz, el viento de Levante, que destaca por tener unas medias de velocidad aproximados de 60-70 km/h, con rachas aún más fuertes y duración de varios días ininterrumpidos (Wheeler, 1995). Esto supone una evidencia empírica del conocimiento que Columela tiene de la zona y además una prueba indirecta de que las condiciones climatológicas no han podido cambiar tanto desde los momentos en los que escribe el autor.

Por tanto, aquí se halla una contradicción de criterios con la recomendación ideal que hace el autor de los lugares para elegir la viña (Columella, Rust. 4.22.):

Además, son defectos del lugar, que llevan generalmente a los viñedos a su ruina, la debilidad y la esterilidad de la tierra, la humedad salada o amarga, la posición inclinada y escarpada, un valle demasiado sombrío y al que no le da el sol... ${ }^{6}$.

Ya conocemos la problemática de la tierra y de la inclinación, a lo que tenemos que unir en este caso la humedad salada o amarga y el valle sombrío. En cuanto a la humedad, supondrá un límite geográfico para no poner las viñas en suelos con una composición salina muy importante o excesivamente cerca de la costa.

4. Democrito et Magone laudantibus caeli plagam septentrionalem, quia existiment ei subiectas feracissimas fieri vineas, quae tamen bonitate vini superentur. Nobis in universum praecipere optimum visum est, ut in locis frigidis meridiano vineta subiciantur; tepidis orienti advertantur, si tamen non infestabuntur Austris Eurisque velut orae maritimae in Baetica. Sin autem regiones praedictis ventis fuerint obnoxiae, melius Aquiloni vel Favonio committentur.

5. Pero el suelo que es fuerte y empapado de suave humor, y el campo de hierbas cubierto y de gran fertilidad, cuál es el que solemos contemplar muchas veces en el hondo de un valle excavado en la montaña (donde se deslizan los ríos desde las elevadas rocas arrastrando fecundante limo), y lo mismo el suelo que se levanta orientado al Austro y cría el helecho, odiado por el corvo arado, este tal será el que un día te proporcionará robustas vides, que manaran abundante vino, este es en uvas fértil, fértil en vino, cuál es el que libamos en pateras de oro, cuando el grueso Tirreno ha soplado en su flauta de marfil junto a las aras y ofrendamos las entrañas humeantes sobre platos que se encorvan bajo el peso. at quae pinguis humus dulcique uligine laeta, quique frequens herbis et fertilis ubere campus, qualem saepe caua montis conualle solemus despicere (huc summis liquuntur rupibus amnes felicemque trahunt limum), quique editus Austro et filicem curuis inuisam pascit aratris: hic tibi praeualidas olim multoque fluentis sufficiet Baccho uitis, hic fertilis uuae, hic laticis, qualem pateris libamus et auro, inflauit cum pinguis ebur Tyrrhenus ad aras, lancibus et pandis fumantia reddimus exta. Tus vinedos no estén orientados hacia el sol poniente. Neue tibi ad solem uergant uineta cadentem.

6. ...oci porro vitia sunt, quae fere ad internecionem vineta perducunt, macies et sterilitas terrae, salsa vel amara uligo, praeceps et praerupta positio, nimium opaca et soli aversa vallis... 
Respecto a la orientación por insolación, sin duda interesará colocar las viñas hacia el sur, ya que es donde más horas de sol van a recibir.

De nuevo se trata de un criterio modelable gracias a herramientas SIG como Spatial Tools/Surface/Orientation, que nos devuelve sobre un modelo digital la orientación del terreno respecto a los puntos cardinales (Figura 4). De esta manera, es posible comprobar los lugares idóneos respecto al viento gracias a estas herramientas, junto con el análisis de sus implicaciones.

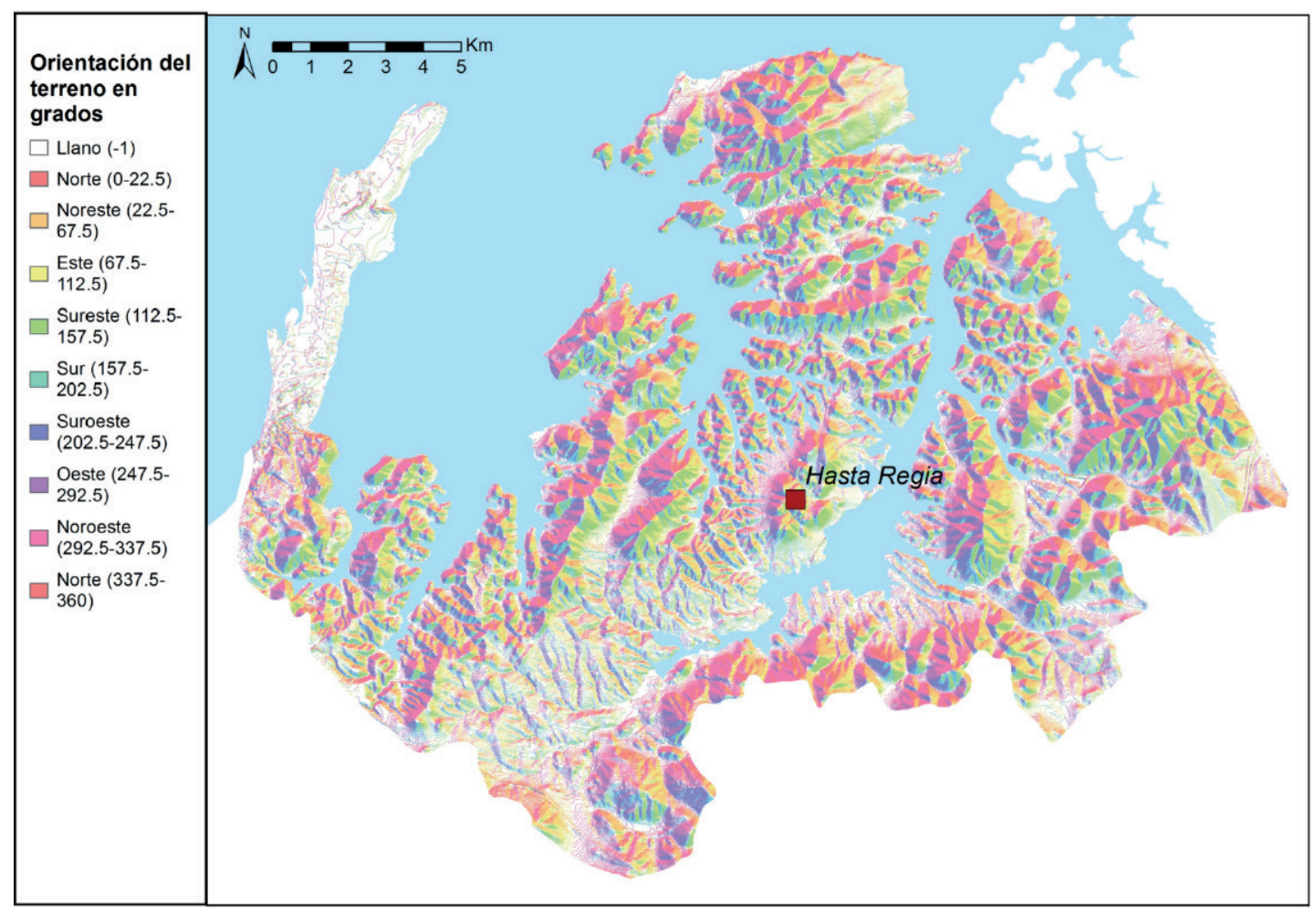

Figura 4. Representación de la orientación del territorio respecto a los puntos cardinales. Fuente: Elaboración propia.

\section{RESULTADOS}

Al igual que con la metodología en los resultados vamos a valorar cada criterio agronómico con respecto a la actualidad, para nuestro caso de estudio. Esto es posible gracias a que tenemos datos que pueden asociarse y que dan buena cuenta de dónde se localizarían las viñas y cuáles son los condicionantes ideales para colocarlas. Se trata de referencias a su tío Marco (Columella, Rust 2.15.4.):

Si no hay ninguna clase de estiércol, conviene mucho hacer lo que recuerdo que mi tío paterno, Marco Columela, labrador muy preparado y trabajador, realizaba en muchas ocasiones: echar greda en los terrenos arenosos y arena en los gredosos y excesivamente densos. Obtuvo así no sólo abundantes mieses, sino que logró también viñas muy hermosas. Afirmaba él que en las viñas no se debe echar estiércol, porque corrompe el sabor del vino, y pensaba que era mejor materia para lograr una vendimia abundante la tierra amontonada al azar o la procedente de los abrojos, o por último cualquier otra traída de otro lugar?

7. Si tamen nullum genus stercoris suppetet, ei multum proderit fecisse, quod Marcum Columellam patruum meum, doctissimum et diligentissimum agricolam, saepe numero usurpasse memoria repeto, ut sabulosis locis cretam ingereret, cretosis ac nimium densis sabulu, atque... ligone succident, vim optimae stereorationis exhibebit. Succidi autem lupinum sabulosis locis oportet, cum secundum florem, lubricosis, eum tertium egerit. Nam idem negabat stercus vitibus ingerendum, quod saporem vini corrumperet; melioremque censebat esse materiam vindemiis exuberandis, congesticiam vel de vepribus vel denique aliam quamlibet arcessitam et advectam humum. 
Complementario a este fragmento, tenemos otro en referencia a las viñas palustres (Columella, Rust 12.21.5-6):

Mi tío paterno Columela, ilustre agricultor, solía emplear esta fórmula de aderezo en aquellas propiedades en las que tenía viñas cenagosas. Pero cuando él aderezaba vinos de vides de monte, añadía, en lugar de sal, agua salada cocida hasta quedar en un tercio. Ésta, sin duda, aumenta la cantidad de vino y le da mejor olor, pero tiene el peligro de que el vino se echa a perder si el agua está mal hervida; se toma ésta, según ya había dicho, lo más lejos posible de la costa, pues es más líquida y más pura cuanto de más alta mar se ha cogido. Si alguno, como hacía Columela, la guarda y al cabo de tres años la depura y la trasvasa a otras vasijas, y luego tras otro período de tres años la cuece hasta que se reduzca a un tercio, tendrá mucho mejor aderezo para el vino y no habrá peligro ninguno de que los vinos se echen a perder ${ }^{8}$.

Estas dos referencias son claves para comprender bien la tipología de suelos que se utilizaron para las vides. Marco Columela parece tener varias fincas, por las descripciones que nos da, donde además tiene distintos tipos de viñas (Marín y Prieto 1985). Sáez Fernández identifica a la cretam con los regosoles calcáreos, albarizas, mientras que el sabulum serían los suelos de arenas, que también son muy utilizados en la actualidad (Sáez, 1987, p. 12). En el marco actual de Jerez, productor de vinos de denominación de origen, los suelos más utilizados son las albarizas, seguidos de las arenas y continuados por los bujeos. Precisamente, es este tipo de suelo el que Sáez identifica como las vineas palustres.

\subsection{Sabulosis y cretosis}

Con respecto a estas cuestiones, es relevante analizar las referencias a sabulosis y cretosis. La primera puede ser probablemente identificada correctamente con arenas, posiblemente con la categoría edafológica de arenosoles, aunque también luvisoles, ya que estos son en la práctica un suelo arenoso y arcilloso, pero que destacarían principalmente por su primera acepción. Otros términos empleados son más complejos a la hora de asignarles un significado. Para el caso de cretam y cretosis, el término actual debería de ser greda, si bien no queda claro en la literatura agronómica su correcta interpretación. Varrón $(R . R .1 .7 .8)^{9}$ se refiere a un suelo de creta, en un viaje a la Galia, en la que ve enriquecer la tierra, con margas de cantera. Con Virgilio (Geor. 2.215) ${ }^{10}$ se puede ver claramente la diferencia entre este término y otros que pudieran generar confusión, como grava glarea. En ambos casos se trata de referencias que no tienen relación con la greda, sino más bien con grava, es decir, con pequeños fragmentos de piedras.

La cuestión clave es identificar a qué se refiere Columela con creta (Tabla 3). En sus libros utiliza este término en un total de diecinueve ocasiones. Sin embargo, no parece haber una única acepción clara al término, sino que cambia dependiendo del contexto y del uso que hace el autor del término. Greda, en la actualidad, también es un término con múltiples acepciones. Según la Real Academia Española (RAE) se definiría como "arcilla arenosa, por lo común de color blanco azulado, usada principalmente para absorber grasa y en la fabricación de cerámica". El autor la utiliza con esta acepción en multitud de ocasiones, haciendo en muchos casos la referencia a un tipo específico de arcilla que podríamos denominar como "greda de alfarero"11.. Este

8. Hac conditura Columella patruus meus, inlustris agricola, uti solitus est in his fundis, in quibus palustres vineas habebat. Sed idem, cum collina vina condiebat, aquam salsam decoctam ad tertias pro sale adiciebat. Ea porro facit sine dubio maiorem mensuram et odoris melioris, sed periculum habet, ne vitietur vinum, si male cocta sit aqua; sumitur autem haec, ut iam dixeram, quam longissime ab litore; nam liquidior et purior est, quantum altiore mari hausta est. Eam si quis, ut Columella faciebat, reponat et post triennium in alia vasa eliquatam transfundat, deinde post alterum triennium decoquat usque ad partem tertiam, longe meliorem habebit condituram vini, nec ullum periculum erit, ne vina vitientur. Satis est autem sextarios singulos adicere salsae aquae in binas musti urnas, quamvis multi etiam binos inmisceant, nonnulli etiam ternos sextarios, idque [ego] facere non recusem, si genus vini tantum valeat, ut aquae salsae non intellegatur sapor.

9. In Gallia transalpina intus, ad Rhenum cum exercitum ducerem, aliquot regiones accessi, ubi nec vitis nec olea nec poma nascerentur, ubi agros stercorarent candida fossicia creta...

10. nam ieiuna quidem cliuosi glarea ruris uix humilis apibus casias roremque ministrat; et tofus scaber et nigris exesa chelydris creta negant alios aeque serpentibus agros dulcem ferre cibum et curuas praebere latebras

11. Columella, Rust. 6.17.4. Pero la lesión causada por la primera se cura punzando la parte herida con una lezna de cobre y untándola 
término no es similar a arcilla argila, que él mismo refiere. Hablando de su tío Marco Columela, sobre un tipo de bandejas para conservar la uva de mesa, se aclara que se utiliza la creta, qua fiunt amphorae (Columella, Rust. 12.44.5-6), es decir, el tipo de material con el que se hacen las ánforas. Aquí podemos ver una dualidad en la definición del concepto, en esta arcilla utilizada para ánforas. Ésta puede relacionarse al tipo de desengrasante utilizado, frente a otro concepto de arcilla más depurada para el uso de objetos de una mayor calidad. Siendo esto así, Columela entiende el término cretam figularem como una arcilla mezclada con otros materiales, probablemente arenosos, aunque también pudieran ser de otro origen, volcánicos, como la puzolana, acepción con la que actualmente también se denomina a la greda (Diccionari di Geologia). Esta definición no puede ser a la que se refiere para el caso de las tierras, ya que precisamente la utiliza para hacer esta mezcla entre arenas y greda, con el objeto de enriquecer a ambas, cosa que parece poco probable, caso de que la greda fuera esta arcilla mezclada con otros materiales. Por tanto, es posible que Columela entienda este término en, al menos, dos sentidos.

Cuando habla de tipologías de suelos, utiliza distintos adjetivos de las propiedades del suelo, junto con la greda. Estos son: denso y con greda, en contraposición con tierra más suelta (Columella, Rust. 2.2.9.) ${ }^{12}$; denso, gredoso y húmedo (Columella, Rust. 2.9.3 y 2.9.5) ${ }^{13}$; gredoso o seco, en contraposición con tierra ligera, suelta y arenosa (Columella, Rust. 2.9.17.) ${ }^{14}$; gredosa frente a tierra débil y sobre todo roja (Columella, Rust. 2.10.3. $)^{15}$.

Por estas definiciones, parece ser que la greda es una tierra compacta y densa, especialmente por la contraposición de suelta y ligera. Parece también ser lo contrario a las arenas, aunque también a las tierras rojas. Pudiera parecer que Columela se refiere a este término de una manera de suelos arcillosos, que pueden resultar compactos y que a su vez pueden ser enriquecidos con arenas o similares para mejorar las características del mismo. Sin embargo, cuando hace especial mención a este tipo de suelos, específicamente para la vid (Columella, Rust. 3.11.9.) ${ }^{16}$ o el olivo (Columella, Rust. 5.8.6.) ${ }^{17}$, en realidad, se está refiriendo a algo similar

con greda de Cimola desleída en vinagre. Sed illius sanatur noxa subula aenea, si locum laesum compungas, cretaque cimolia ex aceto linas. Columella, Rust. 6.17.6. Es frecuente también encerrar la musaraña viva en arcilla de alfarero; cuando se ha secado la arcilla, se cuelga del cuello de los bueyes. Solet etiam ipsum animal creta figulari circumdari; quae cum siccata est, collo boum suspenditur. Columella, Rust. 6.17.6Con todo, no sufren la castración por haber perdido los órganos genitales, sino quemándoles con hierro candente los espolones, que, cuando han sido consumidos por la fuerza del fuego, se untan con arcilla de alfarero, hasta que sanan las heridas hechas. Nec tamen id patiuntur amissis genitalibus, sed ferro candente calcaribus inustis, quae cum ignea vi consumpta sunt, facta ulcera dum consanescant, figulari creta linuntur. Columella, Rust. 10.60. ...es bien cierto que aquélla creó las arcillas Prometeas.... Ista Prometheae genetrix fuit altera cretae. Columella, Rust. 12.46.5. Pero también recomienda el mismo autor untar las granadas frescas con una capa espesa de greda de alfarero bien amasada y colgarlas, cuando la arcilla se ha secado, en un sitio fresco; y luego, en el momento en que la necesidad lo requiera, introducirlas en agua y deshacer la greda. Sed et idem auctor est creta figulari bene subacta recentia mala crasse inlinire et, cum argilla exaruit, frigido loco suspendere, mox, cum exegerit usus, in aqua demittere et cretam resolveré. Columella, Rust. 12.46.7 y 12.47.1 Muchos arrancan del árbol los membrillos con sus ramitas y, tras haberlos cubierto cuidadosamente con greda de alfarero, los secan al sol; luego, si la greda formó grietas, las cubren con barro y, una vez secos, los cuelgan en sitio fresco. Muchos conservan los membrillos en hoyos o en tinajas, de la misma forma que las granadas; otros los atan con hojas de higuera, amasan luego greda de alfarero con alpechín... Multi cum ramulis suis arbori detrahunt et, creta figulari cum diligenter mala obruerunt, in sole siccant, deinde, si qua rimam creta fecit, luto linunt et adsiccata frigido loco suspendunt. Multi eadem ratione, qua granata, in scrobibus vel dolis servant cydonea, nonnulli foliis ficulneis inligant, deinde cretam figularem cum amurca.

12. En los parajes densos y abundantes en greda se dejan abiertas; pero donde la tierra es más suelta, si bien algunas se dejan también al descubierto, otras sin embargo se ciegan de forma que a ellas vengan a desembocar las que quedaron abiertas". Spissis atque cretosis regionibus apertae relinquuntur; at ubi solutior humus est, aliquae fiunt patentes, quaedam etiam obcaecantur, ita ut in patentes ora hiantia caecarum competant; sed patentes latius apertas summa parte declivesque et ad solum coarctatas, imbricibus supinis similes facere conveniet.

13. La tierra densa, gredosa y húmeda proporciona bien trigo candeal y escaña. Densa cretosaque et uliginosa humus siliginem et far adoreum non incommode alit. Si el campo es medianamente gredoso o húmedo.... si mediocriter cretosus uliginosusve ager est.

14. Requieren una tierra ligera y suelta y no sólo se reproducen en un suelo arenoso, sino incluso en arena, con tal que el clima sea húmedo o el terreno regado, pues temen al seco y al gredoso. Nec in sabuloso solo, sed in arena quoque proveniunt, modo humido caelo vel riguo solo. Nam siccum cretosumque reformidan

15. Como dije, necesita tierra débil y sobre todo roja, pues teme a la gredosa y no se reproduce en un terreno húmedo. Id, ut dixi, exilem amat terram, et rubricam praecipue. Nam cretam reformidat limosoque non exit agro.

16. La tierra gredosa se considera útil para la vid, pero la greda sola, de la que se sirven los alfareros y a la que algunos llaman arcilla, le va muy mal, y, no menos, la arena sola y todo lo que, como dice Julio Atico, reseca la planta. Cretosa humus utilis habetur viti: nam per se ipsa creta, qua utuntur figuli, quamque nonnulli argillam vocant, inimicissima est; nec minus ieiunus sabulo, et quicquid, ut ait Iulius Atticus, retorridum surculum facit.

17. El tipo de terreno más apto para los olivos es el que tiene grava en el fondo, y, encima, una capa de arcilla mezclada con arena. 
a la arcilla, como él mismo dice, nam per se ipsa creta, qua utuntur figuli, quamque nonnulli argillam vocant, es decir, la greda que utilizan los alfareros, que algunos llaman arcilla (Galan y Aparicio, 2006). Creemos que queda claro que se trata de dos cosas distintas, que Columela sabe diferenciar, pero cuya correspondencia puede haber pasado desapercibida en nuestros días.

Con todo ello, nos interesa conocer cómo diferenciaban estos suelos en el mundo antiguo. Sin duda, un suelo de margas yesíferas o calcáreas tiene un comportamiento plástico que resulta difícil por sí mismo para el cultivo, ya que pueden resultar tierras muy ácidas, con alto contenido en carbonato cálcico (AA.W. 1963, p. 170), como es el caso de las calcáreas, dificultando su cultivo. La textura de este tipo de tierras pudiera ser algo parecido a la greda descrita por Columela, que no es arcilla sino otra cosa, que se utilizaba para la cerámica de almacenamiento y transporte, como aditivo y que tiene relación con algún tipo de suelo que se suele mezclar con otros más sueltos, ya que así mejora sus características para el cultivo. Este tipo de suelo es el propuesto por Sáez (1987) como las denominadas albarizas y que son los suelos actualmente preferidos para el cultivo de la vid en el Marco de Jerez. Por ello creemos que queda aclarada la relación directa entre este tipo de tierra y la referencia de Columela, a través de las descripciones de este mismo autor en otros fragmentos de su obra.

Tabla 3. Síntesis de los términos analizados y su posible correlación actual.

\begin{tabular}{|l|l|l|l|}
\hline \multicolumn{1}{|c|}{ Término latino } & \multicolumn{1}{|c|}{ Autor y referencia } & \multicolumn{1}{c|}{ A que hace referencia } & \multicolumn{1}{c|}{ Posible término actual } \\
\hline Creta & $\begin{array}{l}\text { Var. R.R. 1.7.8; Verg. Geor. } \\
2.215\end{array}$ & $\begin{array}{l}\text { Pequeños fragmentos de } \\
\text { piedra }\end{array}$ & Grava \\
\hline Creta & $\begin{array}{l}\text { Columella, Rust. } 6.17 .4 ; \\
6.17 .6 ; 6.17 .6 ; 10.60 ; \\
12.46 .5 ; 12.46 .7 \text { y } 12.47 .1\end{array}$ & $\begin{array}{l}\text { Arcilla arenosa, utilizada en } \\
\text { alfarería, “greda de alfare- } \\
\text { ro". Diferente a arcilla. }\end{array}$ & Greda \\
\hline Cretosis & $\begin{array}{l}\text { Columella, Rust. } 2.2 .9 ; 2.9 .3 ; \\
2.9 .5 ; 2.9 .17 ; 2.10 .3\end{array}$ & $\begin{array}{l}\text { Propiedad del suelo com- } \\
\text { pacta y densa, contraria a } \\
\text { arenas y tierras rojas }\end{array}$ & Sin término actual \\
\hline Creta & $\begin{array}{l}\text { Columella, Rust. 3.11.9; } \\
5.8 .6 .\end{array}$ & $\begin{array}{l}\text { Tierra similar a la arcilla que } \\
\text { en época romana podría } \\
\text { confundirse }\end{array}$ & Margas \\
\hline Sabulosis & $\begin{array}{l}\text { Columella, Rust. } 2.9 .17 ; \\
2.15 .4 ; 3.11 .9 ; 5.8 .6 .\end{array}$ & $\begin{array}{l}\text { Suelo con componente de } \\
\text { arena }\end{array}$ & Arenoso \\
\hline
\end{tabular}

Fuente: Elaboración propia.

\subsection{Palustres vineas}

Con respecto al otro tipo de suelos descrito, Marco Columela tenía unas viñas palustres, palustres vineas (Columella, Rust. 12.21.5-6). Resulta poco probable hablar de viñas en zonas inundables, como podamos pensarlo en el sentido actual del término, especialmente porque las variedades de uva en Jerez están más habituadas a altas temperaturas que a la humedad. De hecho, una humedad excesiva puede ser mortal para la planta. Es poco probable, por tanto, que estemos hablando de viñas que estén en una zona con un alto contenido de agua. En su lugar, nos inclinamos a pensar en otras opciones.

La primera de ellas podría ser unas viñas de regadío, es decir, vides que estén bajo un flujo constante de agua, que pudiera tener sentido si habláramos de uva de mesa, por ejemplo, que puede ser cultivada específicamente cerca de las ciudades y que además pudiera estar bajo regadío, al pertenecer al huerto de a villa (Rodríqu ez 2008; Buzón 2016 ). Sipombarier vigorosa y fértil, da buena acogida a

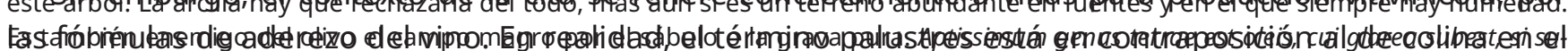

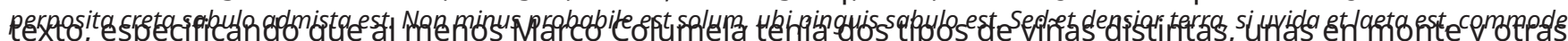
recipit hanc arborem. Creta ex toto repudianda est, magis etiam scaturiginosa et in qua semper uligo consistit. Inimicus est etiam ager sabulo endlep et huda glarea. 
Para indagar más en estos aspectos, (Tabla 4) es preciso revisar otros fragmentos de Columela donde hace referencia a estas cuestiones. Las menciones a espacios palustres tienen una continua connotación negativa (Cañizar, 2016) que suelen acompañar en la literatura a estos espacios (Columella, Rust, 1.5.3.), resaltando la diferencia entre los paludes, que tienen agua totalmente estancada de los que no, siendo mejores en los que hay algo de movimiento de sus aguas, en este caso, hablando del agua para el consumo y los animales. En otros, la referencia a palustres parece tener una relación con espacios fríos (Columella, Rust. 2.11.2.) ${ }^{18}$, mientras que, a su vez, son los sitios donde viven patos y gansos (Columella, Rust. 2.14.1.) ${ }^{19}$, siguiendo la lógica de asociarlos a espacios de humedal, que es la acepción más general del término. Sin embargo, hay sutiles matizaciones en la obra de Columela, donde no sólo la encontramos para los paludes o zonas inundadas, como pudieran ser lagunas, muy interesantes de cara al estudio de las "Riparia" (Hermón, 2010, 2014; Peyras, 2014), sino que el término se refiere a zonas que, de manera excepcional, se puedan encontrar con agua. Es, por ejemplo, la acepción que encontramos en referencia a zonas encharcadas que deben ser desviadas mediante zanjas, especialmente para los pastos (Columella, Rust. 2.16.) ${ }^{20}$. También está en la recomendación sobre el suelo óptimo para los cerdos (Columella, Rust. 7.9.6.) ${ }^{21}$, que pueden criarse en cualquier terreno, pero se recomienda uno empantanado, frente a otro falto de agua. Respecto a elegir el mejor lugar para los caballos, nos recomienda sitios espaciosos y palustres (Columella, Rust. 6.27.2. $)^{22}$.

En este último caso, la asimilación de palustres y zonas de regadío se contrapone con la de monte y secano. Este puede ser el ejemplo más claro del uso de este término cambiante en Columela, pues no sólo lo refiere a lagunas, estacionales o no, sino también a cualquier charca, en contraposición a zonas de secano.

Para definir el tipo de suelo podemos seguir la línea directora que sitúa P. Sáez Fernández (1987, pp. 1024), sobre su asimilación con las tierras de bujeo. Los vertisoles son tierras generalmente de composición arcillosa, que se vuelven muy plásticas con el agua, reteniéndola y, en determinados momentos del año, inundándose. Estas tierras se agrietan durante el verano, por la compactación de las arcillas ante la falta de agua. Puede que Columela se esté refiriendo a este tipo de suelos, que además suelen estar en zonas bajas, de llanura y que pueden venir asociados a zonas de escorrentía de arroyos. La otra posibilidad pudiera ser la asimilación con zonas de cuenca del río, edafológicamente fluvisoles, que pueden estar parcialmente inundados, siempre y cuando se hagan obras para retener la subida de las aguas.

Probablemente nos encontremos en esta descripción con el primer tipo de suelos, los vertisoles ya que, para el caso de los fluvisoles, suelen depender de un correcto drenaje para que puedan ser utilizados para la mayoría de los usos agrícolas. Si hablamos de los vertisoles, esta dualidad de seco-húmedo es una constante que no se puede controlar, más allá de realizar las zanjas antes mencionadas para desaguar.

La cuestión es que para la vid en hoyos se aconseja que tenga piedras en el agujero, ya que ayuda a apartar las aguas del invierno y los calores de verano (Columella, Rust. 3.15.3. $)^{23}$. Las viñas pueden desarrollarse

18. ...y esto debería hacerse antes del invierno y repetirse después de él; en los terrenos fríos y pantanosos, por lo general, se debe escardar pasado el invierno, y no recubrir de tierra, sino removerla con un escardeo nivelado. In locis autem frigidis et palustribus plerumque transacta hieme sarriri, nec adobrui, sed plana sarritione terram permoveri.

19. ...exceptuamos las que viven en lugares pantanosos o son nadadoras, como el pato y el ganso, pues éste incluso es dañino. exceptis tamen palustribus ac nantibus, ut anatis et anseris; nam id noxium quoque est.

20. ...así, si en alguna parte se forma una charca de agua estancada, ha de desviarse con zanjas, puesto que tanto la abundancia como la carencia de agua supone la desaparición de las hierbas. Itaque si palus in aliqua parte subsidens restagnat, sulcis derivanda est. Quippe aquarum abundantia atque penuria graminibus aeque est exitio.

21. Además, este ganado aprovecha cualquier disposición del terreno Pace perfectamente tanto en montes como en llanos, aunque mejor en campos pantanosos que faltos de agua. Omnem porro situm ruris pecus hoc usurpat, nam et montibus et campis commode pascitur, melius tamen palustribus agris quam sitientibus.

22. Se han de elegir para este tipo de ganado pastos espaciosos y palustres, no montañosos, de riego, jamás de secano, mejor rasos que llenos de troncos de árboles y abundante en hierbas espesas y tiernas mejor que altas. Gregibus autem spatiosa et palustria, nec [non] montana pascua eligenda sunt, rigua, nec umquam siccanea, vacuaque magis quam stirpibus impedita, frequenter mollibus potius quam proceris herbis abundantia

23. Parece que estas piedras, según dice Magón, apartan de las raíces las aguas del invierno y los calores del verano, y Virgilio, siguiéndole, aconseja que se preserven y fortifiquen las plantas así. Hi videntur, ut Mago prodit, et aquas hiemis et vapores aestatis propulsare radicibus; quem secutus Virgilius tutari semina et muniri sic praecipit. 
Tabla 4. Síntesis de los términos analizados y su posible correlación actual.

\begin{tabular}{|l|l|l|l|}
\hline \multicolumn{1}{|c|}{ Término latino } & \multicolumn{1}{|c|}{ Autor donde aparece citado } & \multicolumn{1}{c|}{ A que hace referencia } & \multicolumn{1}{c|}{ Posible término actual } \\
\hline Paludes & Columella, Rust, 1.5.3. & $\begin{array}{l}\text { Espacios de ribera estacional } \\
\text { o no }\end{array}$ & Ribera o lagunas \\
\hline Paludes & Columella, Rust. 2.11.2. & Espacios fríos & Sin término actual \\
\hline Paludes & Columella, Rust. 2.14.1. & $\begin{array}{l}\text { Espacios donde viven patos y } \\
\text { gansos }\end{array}$ & Posible Alberca \\
\hline Palus palustribus & $\begin{array}{l}\text { Columella, Rust. 2.16; 7.9.6; } \\
\text { 6.27.2. }\end{array}$ & $\begin{array}{l}\text { Zonas que anualmente pue- } \\
\text { den quedar bajo agua }\end{array}$ & Tierras de regadío \\
\hline Palustres vineas & Columella, Rust. 12.21.5-6 & $\begin{array}{l}\text { Tierras que en alguna esta- } \\
\text { ción quedan encharcadas }\end{array}$ & Viñas en tierras de vertisoles \\
\hline
\end{tabular}

Fuente: Elaboración propia.

en climas fríos, pero requieren de una gran adaptación, incluso en la actualidad. Sin duda, debemos hablar de zonas cuya tierra se pueda definir como muy húmeda en una determinada época de año, pero no de manera constante, ya que podría llegar a pudrir las raíces (Hidalgo, 2003).

Es por ello que debemos descartar a priori la descripción hecha por Columela de los fluvisoles, los cuales requerirían una labor de infraestructura previa de drenaje de estas áreas. Sin embargo, los vertisoles o bujeos se encharcan bajo una lluvia intensa, reteniendo el agua solamente por unos pocos días. Coincide también que la tercera tierra en calidad de vinos en el Marco de Jerez es este tipo concreto de suelo.

\subsection{Pendientes y orientación del terreno}

Estos dos criterios son más fáciles de ponderar en un modelo ya que tienen una asimilación más sencilla con la actualidad. En el caso de la pendiente del terreno, como ya se ha comentado en la metodología, existe una unanimidad a considerar las zonas de dehesa o medio monte como ideales para la viña, mientras que el llano se reserva para otros productos como el trigo. La relación en los criterios agronómicos con los actuales no ofrece duda a su interpretación y en todo caso, se trata del nivel de pendiente que vayamos a considerar en nuestro modelo.

Sin embargo, la doble orientación del terreno, si puede ser un tema a debatir (Tabla 5). Debemos suponer que los productores romanos tendrían en cuenta estos criterios a la hora de elegir donde plantar sus vides. La insolación no debió ser un criterio fundamental, como el tipo de suelo o la pendiente del terreno, ya que la orografía en la zona no es muy pronunciada. El rendimiento productivo de los campos puede variar mucho dependiendo de zonas que tengan menos horas de insolación, si bien éste es un criterio que se aplicaría principalmente a valles sombríos entre montañas y que poca incidencia tiene en nuestra área, siendo de importancia si nos dirigimos hacia la sierra de Cádiz. Pese a ello, igualmente se tendría en cuenta el criterio, ya que se elegiría la zona Norte de las colinas para otros aprovechamientos que no requieran insolación.

No obstante, esta cuestión se contrapone con la recomendación de Columela para la Bética (Columella, Rust. 2.3.6.), es decir, sí es mejor plantar hacia el Norte y el Oeste. Esto no se debe exclusivamente a los vientos de Levante, que en realidad tienen una orientación hacia el Sureste. También existen en verano vientos cálidos que vienen desde África, calima, que suponen un aumento de las temperaturas, junto con gran sequedad. Tanto el Levante como este fenómeno nos dan idea de la continuidad climática y que se desaconseje el cultivo orientado al Sur y Este. Dado que la vid es susceptible a la sequedad por estos vientos, los agricultores de la zona deberían de haber tenido en cuenta este criterio, con objeto de proteger sus cultivos.

A pesar de lo ya comentado, queremos nombrar una última referencia, que viene a reforzar la idea de la peligrosidad de estos vientos y a añadir otra problemática al debate (Columella, Rust. 5.5.15): 
Ciertamente mi tío paterno, Marco Columela, hombre erudito en ilustres disciplinas y cuidadosísimo agricultor de la provincia Bética, protegía las viñas sombreándolas con esteras de palmas al comienzo de la canícula, ya que por lo general, en dicha estación, algunas partes de la citada región quedan tan devastadas por el Euro, al que los habitantes denominan Vulturno, que si las vides no se sombrearan cubriéndolas, el fruto se quemaría como con un soplo de fuego ${ }^{24}$.

Marco Columela debió poseer viñedos que serían azotadas por este viento $y$, por tanto, ingenia una manera de proteger los frutos de las vides. Esto hace pensar que su tío tenía viñas precisamente en estas regiones donde el viento soplaba con gran intensidad y que, además, no estaban en una posición protegida. Hay que partir de la base que, aunque se pondere la zona Oeste frente a la Este de una colina, esto no supone una protección total de estos vientos. De la misma manera, la elección de las tipologías de suelos dentro de una determinada finca puede estar muy condicionada por los elementos que ya existen, frente a los que podamos especular. A pesar de ello, parece claro que el efecto de este viento modificaba de manera importante la forma de cultivo de la vid en la zona.

\subsection{Modelado de las zonas idóneas para viñas}

Con los datos analizados se puede elaborar un modelo de zonas óptimas para el viñedo. Para ello hemos utilizado Arcgis y herramientas de conversión de polígono a raster, en el caso de los tipos de suelos; mientras que en todos los casos herramientas de reclasificación de datos. De esta manera se asocian valores a cada tipo, de manera que después puedan mezclarse mediante la calculadora raster. Este es un proceso por el cual podemos unir en una misma capa todas las anteriores, pudiendo evaluar visualmente esta combinación. La dificultad está en el peso específico de cada valor y en los distintos rangos en los que se han cambiado los valores. como los elaborados en artículos). El método para ponderar los distintos valores de estos modelos ya ha sido testeado y publicado anteriormente (Trapero 2016a, 2016b; Lagóstena y Trapero, 2019), siendo un proceso que requiere de más investigaciones, en otros casos de estudio, para poder afinar la mejor combinación (Stubert et all. 2020).

En la figura 5 se compara las distintas zonas óptimas de viñedos, con los viñedos actuales en el Marco de Jerez, así como con una capa de poblamiento de villas romanas del entorno (2020). Como se puede observar hay cierta identificación entre las áreas óptimas con la dispersión del poblamiento villático en la zona. Este es un resultado relevante ya que no se ha hecho comparativa con la información arqueológica de la zona. También se ha hecho la comparación con las zonas actuales de viñedo donde podemos destacar las que están asociadas a ciudades, al norte Trebujena; mientras que, al Sur, Jerez de la Frontera.

24. M. Quidem Columella patruus meus, vir illustribus disciplinis eruditus ac diligentissimus agricola Baeticae provinciae, sub ortu caniculae palmeis tegetibus vineas adumbrabat, quoniam plerumque dicti sideris tempore quaedam partes eius regionis sic infestantur Euro, quem incolae Vulturnum appellant, ut nisi teguminibus vites opacentur, velut halitu flammeo fructus uratur. 
Tabla 5. Síntesis de los términos analizados y su posible correlación actual.

\begin{tabular}{|l|l|l|}
\hline \multicolumn{1}{|c|}{ Autor } & \multicolumn{1}{|c|}{ Referencia } & \multicolumn{1}{c|}{ Recomendación } \\
\hline Columela & Rust. 3.12.6 & $\begin{array}{l}\text { En lugares fríos al Sur, en cálidos al Este, Salvo donde haya vientos fuertes } \\
\text { de esta dirección con en la Bética, donde es mejor al Norte y Oeste. }\end{array}$ \\
\hline Columela & Rust. 4.22. & $\begin{array}{l}\text { No es recomendable plantar la viña en un valle demasiado sombrio (Norte } \\
\text { de una colina) }\end{array}$ \\
\hline Columela & Rust. 5.5.15 & $\begin{array}{l}\text { Marco Columela cubría las viñas con hojas de palma para protegerlas del } \\
\text { viento }\end{array}$ \\
\hline Virgilio & Geor. 2.184-194 y 2.298 & Orientación al Este y Sur \\
\hline
\end{tabular}

Fuente: Elaboración propia.

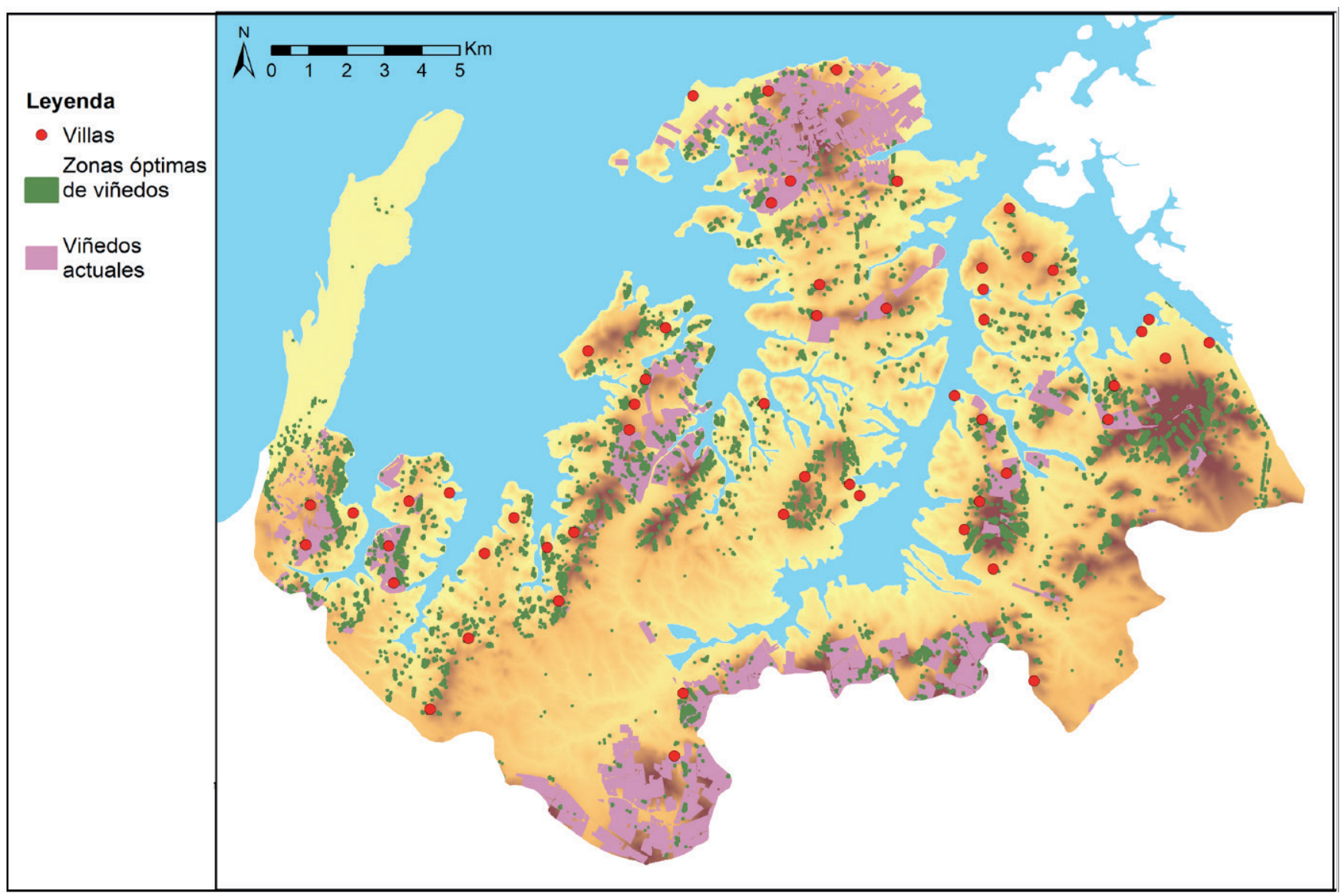

Figura 5. Cálculo de zonas óptimas de viñedo comparado con los viñedos actuales. Fuente: Elaboración propia.

\section{DISCUSION}

Podemos analizar dos ideas principales. La primera nos muestra un cultivo importante de la vid y un interés por el mayor rendimiento de la misma, ya que Marco utiliza una técnica, que, de una manera u otra, supondría un mayor trabajo y coste de las viñas. Esta forma peculiar de protección podría ser utilizada por otros en la zona, aunque esto es una suposición, pues no sabemos si la práctica es invención romana o ya se utilizaba aquí, pudiendo existir la posibilidad que fuera una reminiscencia anterior (Borrego, 2015). Puede que Marco Columela tuviera la innovadora idea de buscar un mayor rendimiento económico. Ahora bien, también es factible que, dadas las condiciones problemáticas con el viento en la zona, ésta fuera una práctica habitual 
de los locales. El hecho que se usen regiones malas por el viento puede dar idea que las buenas, casi con toda probabilidad, estarían utilizadas para estos propósitos, siempre y cuando la disponibilidad de tierras y la propiedad lo permitiera.

La segunda idea hace referencia a la situación de estos campos que menciona Columela, de los que sabemos además qué tipología de tierra debían tener. El Levante no afecta por igual a toda la provincia de Cádiz, pues su mayor influencia es en las regiones costeras, desde Algeciras hasta la boca del Guadalquivir (Wheeler, 1995). Sin embargo, en pleno corazón del territorio de Hasta, actualmente la influencia de este viento es residual, es decir, no tiene la misma importancia que en la costa. Por tanto, las tierras que menciona de Marco Columela, casi con toda probabilidad, se situarían en una franja costera en lugar de hacia la sierra o hacia el interior del bajo Guadalquivir.

Interesa hacer notar una cuestión latente en la descripción de Columela. Cuando dice que Austris Eurisque velut orae maritimae in Baetica (Columella, Rust. 3.12.6), se está refiriendo casi con toda seguridad a la zona de la provincia de Cádiz, si acaso, a una parte de Huelva, ya que la influencia de estos vientos en las actuales costas de las provincias de Málaga, Granada o Almería no tiene este efecto, de hecho, es un viento más húmedo (Viedma, 1998). Esta generalización puede servir como dato para la situación de las citas que conocemos por parte de Columela para su tío, ya que sabemos que estos vientos no tienen gran influencia hacia el interior y que, en las zonas del Sureste de la Península Ibérica, pueden ser positivos, por lo que las citas que estamos describiendo se circunscriben con toda seguridad a una zona, si no en el territorio estudiado, muy cercana.

Finalmente, la relación que realiza Sáez (1987) sobre los tipos de tierra idóneos para la viticultura en nuestra región nos parece correcta, al menos para una zona cercana a la ciudad de Gades. El análisis de estas fuentes de información nos permite conocer de primera mano el conocimiento agronómico sobre los suelos que, a pesar de distar mucho del actual, tiene la capacidad de adaptarse y poder explicar gran parte de los fenómenos físicos que ocurren en la naturaleza. Por tanto, la elección de la zona idónea para la viticultura está condicionada por una serie de parámetros, principalmente la tipología de suelo, pendiente y orientación de la misma, ya sea en protección de vientos o en búsqueda de insolación. Gracias a ello, se pueden proponer zonas de idoneidad para el cultivo de la vid, a partir de las fuentes agronómicas y su correlación con los factores actuales, de ahí la importancia de esta investigación.

\section{CONCLUSIONES}

Este estudio muestra que es posible realizar correlaciones entre información de las fuentes escritas y condicionantes actuales. El principal objeto del artículo se ha cumplido, analizar las palabras clave que los agrimensores romanos, especialmente Columela, utiliza en la elección del cultivo del viñedo. Estas habían sido relacionadas de una manera general en la bibliografía precedente (Sáez, 1988), pero no tenían un proceso analítico, junto a la comparativa de otras fuentes agronómicas.

Ya conocíamos que los condicionantes principales son los tipos de suelo, pendiente y orientación. De entre ellos, el primero ha resultado más complicado de asimilar con características edafológicas actuales, por el bajo nivel de conocimiento antiguo en estas cuestiones. A esto se une la utilización de un mismo término con distintos significados, como los analizados creta o paludes. Sin embargo, la riqueza de la literatura agronómica permite poder definir cuál es cada una de estas interpretaciones para las palabras, las cuales se aportan en el artículo. Es interesante este estudio ya que estas asociaciones pueden ser claves para interpretar visiones antiguas. Por ejemplo, creta hace alusión a varios tipos de materiales distintos, si bien para el caso de suelos parece identificar a las margas, un tipo de suelo que en propiedades físicas puede confundirse con otras como los suelos de arcilla, pero que los agrónomos antiguos pudieron identificar por cuestiones como el color.

Este tipo de interpretaciones nos permiten acercarnos cada vez más a la mentalidad y al conocimiento natural de estos agrónomos, permitiéndonos a su vez poder mensurar y trasladar condicionantes a la actualidad para modelos SIG. En el área concreta las líneas de estudio se basan en continuar con las prospecciones 
para conocer mejor la cultura material y en cotejar otra serie de informaciones como la toponimia, (Martín, 2018). También puede tener gran potencial de transferencia a otros lugares o periodos históricos, una vez comprendidos cuales son los condicionantes, siempre desde un conocimiento profundo de las fuentes literarias. Recientemente se ha publicado un artículo (Stubert et al. 2020), en el que se pone en contraste este modelo y se testea con otros, resultado en una mejora de la comprensión y en la capacidad de análisis de estas herramientas SIG.

\section{Declaración responsable y conflicto de intereses}

El autor declara que no existe ningún conflicto de interés con relación a la publicación de este artículo.

\section{REFERENCIAS}

AA.VV. (1963). Estudio agrobiológico de la provincia de Cádiz. Cádiz: Instituto Nacional de Edafología y Agrobiología del Consejo Superior de Investigaciones Científicas.

AA.VV. (1998). Geopónica o extractos de agricultura de Casiano Baso. Traducción y comentarios de M.J. Meana, J.I. Cubero y P. Sáez. Madrid.

André, J. (1981). Aspects du vocabulaire agricole latin, Roma.

Arias Abellán, M.C. (1987). Los tratadistas de agricultura y las Geórgicas de Virgilio: coincidencias léxicas. Philologia hispalensis, 2 (1), 133-140. https://doi.org/10.12795/PH.1987.v02.i01.09

Borrego Soto, M.A. (2015). El vino y el cultivo de la vid en Al-Andalus y jerez. Jerez, cultura y vino, 177-193.

Bowman, A. \& Wilson, A. (2013). Introduction: quantifying roman agricultura. In A. Bowman \& A. Wilson (Eds.) The roman agricultural economy: organisation, investment, and production (pp. 45-66). Oxford. https://doi.org/10.7202/1014691 ar

Brun, J.P. (2003). Le vin et l'huile dans la Méditerranée antique. Viticulture, oléiculture et procédés de transformation. París.

Buzón Alarcón, M. (2016). Las villae suburbanas, Las villas romanas de la Bética, Granada, 115-174.

Cañizar Palacios, J.L. (2016). Salubritas e insalubritas. El espacio de los humedales en el imaginario romano. En L. Lagóstena Barrios (Ed.), Lacus autem idem et stagnus, ubi inmensa aqua convenit. Estudios históricos sobre humedales en la Bética (II) (pp. 1-14). Cádiz.

Carreras Monfort, C. (2001). Producción de Haltern 70 y Dressel 7-11 en las inmediaciones del Lacus Ligustinus (Las Marismas, Bajo Guadalquivir). En Congreso Internacional Ex Baetica Amphorae. Conservas, aceite y vino de la Bética en el Imperio Romano (pp. 419-426). Écija.

Carretero Poblete, P.A. (2007). Agricultura y comercio púnico-turdetano en el Bajo Guadalquivir. Bar. Series 1703. Series 1703.

Cubero Salmerón, J.J. (2003) Traducción de Ibn Al Awan. El libro de agricultura de Al Awan. Volumen I y II. Consejería de Agricultura y Pesca.

Cubero Salmerón, J.I. (2010). Traducción de Varrón. Rerum rusticarum. Consejería de Agricultura y Pesca.

Días-Regañón López, J.M. (1998). Traducción de Teofrasto. Historia de las plantas. Gredos.

Dicionari di Geologia (2020, 8 de febrero). https://cit.iec.cat/dgeol/default.asp

el Bouzidi, S. (2003). La conception de la villa rustica chez Caton. Entreprise agricole oú simple ferme rurale? Gerión, (21.1), 167-196.

FAO (2019, 5 de diciembre). http://www.fao.org/soils-portal

Galán Huertos, E. \& Aparicio Fernández, P. (2006). Materias primas para la industria cerámica. En M. A. García del Cura \&

J.C. Cañaveras Jiménez (Coords.) Utilización de rocas y minerales industriales (31-48). Alicante.

García Armendáriz, J.I. (1995). Agronomía y tradición clásica. Columela en España. Sevilla.

García del Barrio Ambrosy, I. (1988). Mapa de suelos de la provincia de Cádiz (1). Jerez de la Frontera.

García Vargas, E., Ferrer Albelda, E. \& García Fernández, F.J. (2008). La Romanización del Bajo Guadalquivir: Ciudad, Territorio y Economía (Siglos II-I a.C.). Mainake 30, 247-270.

Goodchild, H. (2007). Modelling roman agricultura production in the Middle Tiber valley, Central Italy. Birmingham. 
Hermon, E. (dir.) (2010). Riparia dans l'Empire romain. Pour la définition du concept. BAR.

Hermon, E. (2014). L'empire romain: un paradigme du modele de gestión intégrée de Riparia? Riparia 0, 1-21. https://doi. org/10.25267/RIPARIA.2014.v0.01

de Herrera, A. (1818). Agricultura General de Gabriel Alonso de Herrera, I. Madrid.

Hidalgo, J. (2003). Tratado de Enología. Madrid.

Holgado Redondo, A. (1988). Traducción de Columela. De los trabajos del campo. Ministerio de Agricultura, Pesca y Alimentación.

Kolendo, J. (1980). L'agricoltura nell'italia romana. Roma.

Larrea Redondo, A. (1975). La vid y el vino, según Columela. Homenaje nacional a Lucio Junio Moderato Columela. Cádiz.

Lagóstena Barrios, L. (2014). La percepción de la ribera en la costa atlántica de la provincia Hispania Ulterior Baetica. En Lacus Ligutinus, Riparia, un patrimoine culturel. La gestión intégrée des bords de l'eau (pp. 187-199).

Lagóstena Barrios, L. \& Trapero Fernández, P. (2019). La localización de los viñedos de Marco Columela: literatura agronómica y análisis GIS en el interfluvio Guadalquivir-Guadalete. En J. Remesal Rodríguez, V. Revilla Calvo, D.J. Martín-Arroyo Sánchez y A. Martín i Oliveras (Eds.) Paisajes productivos y redes comerciales en el imperio romano (pp. 89-114). Instrumenta 65.

López Amador, J.J. \& Ruiz Gil, J.A. (2007). Arqueología de la vid y el vino en El Puerto de Santa María. Revista de Historia del Puerto (38), 11-36.

Manzanero Cano, F. García Arribas, I. Arribas Hernáez, M.L. Moure Casas, A. \& Sancho Bermejo, J.L. (2010) Traducción de Plinio el Viejo. Historia Natural. Gredos.

Marcone, A. (1997). Storia dell'agricoltura romana. Urbino.

Marín, N. \& Prieto, A. (1985). Observaciones sobre la forma de producción y circulación del vino en la provincia romana de la Bética. En: El vi a l'atiguitat economia producció I comerç al Mediterrani occidental (pp. 369-376).

Martín-Arroyo Sánchez, D. \& Remesal Rodríguez, J. (2018). Modelado GIS de la agricultura romana en un marco coIonial teórico. Vegetación de ribera y viticultura en Hasta Regia. Spal, 27 (1), 211-235. https://doi.org/10.12795/ spal.2018i27.08

Martín-Arroyo Sánchez, D. (2018). Colonización romana y territorio en Hispania. El caso de Hasta Regia. Barcelona.

Martín Gutiérrez, E. (1999). Aproximación al repartimiento rural en Jerez de la Frontera: la aldea de Grañina. En la España Medieval 22, 355-368.

Martín Gutiérrez, E. (2018). Entre la costa y la sierra gaditanas. De los paisajes rurales a la interacción sociedad-medio ambiente en el siglo XV. Arqueología y Territorio Medieval, 25, 227-259. https://doi.org/10.17561/aytm.v25.8

Martín Oliveras, A., Martín-Arroyo Sánchez, D. \& Revilla Calvo, V. (2017). The wine economy in Roman Hispania. Archaeological data and modellization. Instrumenta, 55, 189-238.

Moure Casas, A. (1990). Traducción de Paladio. Tratado de agricultura. Medicina veterinaria. Poema de los injertos, traducción y notas por A. Moure Casas.

Olson, L. (1943). Columella and the Beginning of Soil Science. Agricultural History Society, 17, 65-72.

Perales Alcalá, A.M. (1976). Traducción de Cátón. De Agri Cultura. Madrid: Instituto Histórico del Derecho.

Peyras, J. (2014). Les riparia dans les écrits gromatiques, Riparia, un patrimoine culturel. La gestión intégrée des bords de l'eau (pp. 243-255). Oxford.

Porta, J., López-Acevedo, M. \& Roquero, C. (2003). Edafología para la agricultura y el medio ambiente. Madrid.

RAE. https://dle.rae.es/?w=greda/ Visitado el 18/02/2020

Rees, S.E. (1979). Agricultural implements in prerromano and roman Britain. Oxford.

Revilla Calvo, V. (1995). Producción cerámica, viticultura y propiedad rural en Hispania Tarraconensis (Siglos I a.C. - III d.C.). Barcelona.

Rodríguez López, R. (2008). El huerto en la Roma antigua, su problemática urbanística y agraria. Monografías de derecho romano.

Ruiz Gil, J.A., Lagóstena Barrios, L., Pérez Marrero, J., Martín Mochales, D., Trapero Fernández, P. \& Catalán González, J. (2019). Villae y Figlinae a orillas del Lacus Ligustinus. Análisis GIS y prospección geofísica en el territorium ribereño de Hasta Regia. En J. Remesal Rodríguez, V. Revilla Calvo, D.J. Martín-Arroyo Sánchez \& A. Martín i Oliveras (Eds.) Paisajes productivos y redes comerciales en el imperio romano (pp. 115-138). Instrumenta 65.

Sáez Fernández, P. (1983). Columela, De R. R. XII 52,6 canalis et solea. Habis (14), 147-152. 
Sáez Fernández, P. (1987). Agricultura romana de la Bética. Sevilla.

Sáez Fernández, P. (1988). Sobre algunos tipos de tierras vitícolas de la Bética. Actas I congreso peninsular de Historia Antigua. (pp. 521-531). Coimbra.

Sáez Fernández, P. (1995). El vino en la Bética romana. En J.J. Iglesias Rodríguez, (Ed.), Historia y cultura del vino en Andalucía (pp. 13-32). Sevilla.

Sirago, V.A. (1975). L'agricoltura italiana nel II secolo a.C. Napoles.

Stubert, L., Martín i Oliveras, A., Märker, M., Schernthanner, H. \& Vogel, S. (2020). Viticulture in the Laetanian Region (Spain) during the Roman Period: Predictive Modelling and Geomatic Analysis. Geociences 10 (206), 1-28. https://doi. org/10.3390/geosciences10060206

Tchernia, A. (1986). Le vin de l'italie romaine. E. de francaise de Rome, Roma.

Tovar LLorente, A. (1975). Columela y el vino de Jerez. En Homenaje nacional a Lucio Junio Moderato Columela (pp. 93-99). Cádiz. Trapero Fernández, P. (2016a). Roman viticulture analysis based on Latin agronomists and the applications of a geographic information system in lower Guadalquivir. Virtual Archaeology Review, 7(14), 53-60. https://doi.org/10.4995/ var.2015.4481

Trapero Fernández, P. (2016b). Perspectives about the analysis of Roman viticulture in Guadalquivir estuary river. Riparia 2, 55-74. https://doi.org/10.25267/RIPARIA.2016.v2.03

Trapero Fernández, P. (2020). La viticultura romana en Hasta Regia y el estuario del Guadalquivir. Las prácticas de cultivo, producción y distribución marítima, y su potencial transferencia al actual Marco de Jerez [Tesis doctoral, Universidad de Cádiz].

Vidal, J.L. (1990). Traducción de Virgilio. Georgicas. Madrid: Gredos.

Viedma Muñoz, M. (1998). Análisis de las direcciones de los vientos en Andalucía. Nimbus 1, 153-168.

Wheeler, D. (1995). Early instrumental weather data from Cádiz. A study of late eighteenth and early nineteenth century record. International Journal of Climatology 15, 801-810. https://doi.org/10.1002/joc.3370150707

White, K.D. (1975). Farm equipment of the Roman World. Cambridge.

Witcher, R.E. (2006). Agrarian spaces in Roman Italy: society, economy and mediterranean agricultura. Arqueología espacial: paisajes agrarios 26, 341-359. 